\title{
Learning style awareness and academic performance of students
}

\author{
Arunodaya Barman ${ }^{1}$, Rosniza Abd. Aziž, Yusniza Muhamed Yusoff ${ }^{3}$
}

\begin{abstract}
Introduction: Preferred approach to learning is one's own learning style. Learning style varies from individual to individual. When students learn in different ways; their preferred may be an important determinant of their academic performance. This study intends to explore this approach among the nursing students in Kolej Poly-Tech MARA.
\end{abstract}

Methods: It was pre-test/post-test experimental study. Learning style preferences of nursing students were identified using a VARK learning style inventory. Students were informed of their preferred learning style and how to utilize their learning style strengths to improve learning for better academic performance in a one day workshop. Academic achievements of students in terms of GPA for the three consecutive examinations, two held before and one held after the workshop, were collected from the academic departments. Repeated measure ANOVA was done to compare the GPAs obtained by the students in those three examinations.

Results: The study group of nursing students demonstrated different learning styles, with approximately half having a single predominant style preference. There was a significant improvement in the students' performance after the intervention $(F(1.69,506.92)=237.22, p<0.001)$.

Discussion: Students' awareness of their strengths such as learning style preferences and how to utilize their strengths may improve their academic performance. Students should have awareness of their learning style and how to maximize their learning potential in the very early days of enrolment in the academic institution.

Key words: Learning style, academic performance, nursing education

\section{Introduction}

The demand for nurses has increased tremendously for the past few years due to the rapid progression in the healthcare sector in Malaysia. At least 130,000 nurses need to be trained by the year 2020 in order to meet the nurse-to-resident ratio of 1:200 as required by the World Health Organization (Nursing School and Colleges in Malaysia, 2012).

${ }_{1}^{1}$ Professor, Faculty of Medicine and Health Sciences, Universiti Sultan Zainal Abidin, Malaysia

${ }^{2}$ Lecturer, Department of Medical Education, School of Medical Sciences, Universiti Sains Malaysia

${ }^{3}$ Lecturer, Kolej poly-Tech MARA, Malaysia

Corresponding author:

Arunodaya Barman,

Professor, Faculty of Medicine and Health Sciences, Universiti Sultan Zainal Abidin, Jalan Sultan Mahmud, 20400 Kuala Terengganu, Terengganu, Malaysia

e-mail: abarman@unisza.edu.my
Producing professional and clinically competent nurses is now a challenge to colleges as well as universities. Current nursing education is quite different from that of the past. Kolej Poly-Tech MARA (KPTM) commenced the nursing program in September, 2006 with 150 students. Currently, there are almost 2000 students enrolled for study in Diploma in Nursing at the KPTM nursing campus. Each academic session consists of an in-campus academic phase and a clinical phase. The academic phase takes about 14 weeks where students need to commit to academic activities such as lectures, tutorials and practical in clinical laboratory. The clinical phase duration is between four to sixteen weeks according to the semester. Students are required to practice their skills during the clinical attachment at selected hospitals. 
Students are assessed for their theoretical knowledge and practical skills throughout the semester. Besides continuous assessment such as assignments and reports, they sit for OSCE and written examinations that include MCQs and essay questions. In year one (1st and 2nd semesters), most subjects are at introductory level and considered necessary for the new students who are adapting to the program. After completing six semesters in the nursing program, graduates from KPTM need to sit for the Nursing Board Examination which is compulsory to all nurses before they can start their nursing profession.

In KPTM Kota Bharu, the first batch of 129 students completed their studies in March 2009 and were awarded the Diploma of Nursing by KPTM. All took the Nursing Board Examination (NBE) in May 2009, but only 68 passed, resulting in a high failure rate.

One reason for such a high failure rate may be unawareness of learning styles of the students and under-utilization of the strength of their individual learning style. Learning styles have been shown to have an influence on students' academic achievement, how students learn, and student/teacher interaction (Garton et al., 1999). Learning styles can simply be defined as characteristic ways that learners perceive, interact with and respond to their environment (Grasha \& Hicks, 2000). It is basically an individual's mode of gaining knowledge or their unique approach to learning based on strength, weaknesses and preferences (Kinshuk et al., 2009).

Schroeder (1993) concluded that students are coming to institutions of higher learning with more diversity in their learning styles than ever before. They have different levels of motivation, different attitudes about teaching and learning, and different responses to specific classroom environments and instructional practices. Felder \& Brent (2005) state that one of the categories of diversity that have been shown to have important implications for teaching and learning are differences in students' characteristic ways of taking in and processing information. Understanding our particular learning style and how to best meet the needs of that learning style is essential to achieve better academic performance (Whitney, 2005). Identifying individual students' learning styles and sharing the results with them can provide them with valuable clues about their possible strengths and weaknesses and indications of ways they might improve their academic performance (Felder \& Brent, 2005).

Studies show that appropriate study techniques that matched individual learning style preference will promote better academic performance. (Visser et al., 2006; Felder \& Brent, 2005; Griggs, 1991; Purdie \& Hattie, 1999). O'Brien (1999) proposed that the single most important and yet simple thing a teacher or parent can do for students is to give them the knowledge of what their learning style is and how to use it. Students once realize their learning style and know how to make things fit their needs; they become more proficient learners (Sze, 2009; Sims \& Sims, 2006). Studies also suggested that students' learning style influences their cumulative grade point average (Torres,1993; Torres \& Cano, 1994; Purdie \& Hattie, 1999).

Realizing that students of this study group were not really aware of their own learning style preferences, this experimental study was expected to generate some ideas to help students achieve better results in their academic performance by raising their learning style awareness.

\section{Methods}

A pre and post intervention study was conducted at KPTM Nursing Campus in Kota Bharu. The study was carried out during the academic session of the forth semester student started on fourth July 2009. Three hundred and one (301) of the three hundred and forty four (344) students participated. Learning styles were identified and the students were informed about their individual learning style. Students were taught on how to study and complete their assignment using their individual learning style strengths through a workshop conducted early in the semester. A comparison of GPAs of three successive examinations of this group of students were made; the first two GPAs (without intervention) and the third one on being aware of learning style and study skills (with intervention) in the above mentioned workshop.

The VARK learning style inventory was used to collect data about the learning style preferences of students and academic records (GPA) were collected from the academic office. The VARK method used in this study defines the preference in learning style based on the sensory modality in which a student prefers to take in new information. The major sensory modalities are: visual $(\mathrm{V})$, aural $(\mathrm{A})$ 
read-write $(R)$ and kinesthetic $(K)$, collectively known as VARK (Fleming, 1995). Besides validity and reliability of the inventory, the 16item VARK questionnaire is considered simple and understandable. The students however, were guided by appointed instructors in a small group of twenty five (25) to ensure they really understand the questions and therefore would produce the appropriate answers.

A formal workshop on study techniques appropriate for various learning styles was planned and presented. This workshop was offered in six sessions to cater to the group of three hundred and one 4th semester students. Within this workshop, students first became aware of their preferred learning style(s) followed by multiple study techniques suitable for each style.

Each student's learning style (LS) was categorized to Visual (V), Auditory (A), Read and Write $(R)$, Kinesthetic $(K)$ or multimodal. In addition, the academic performance of the nursing students was recorded as Grade Point Average (GPA) which varied from $0.00-4.00$. The data were processed using Excel 2007 and SPSS (12th version). Repeated measure ANOVA was used in analysing the data to identify any significant differences between mean of the scores (GPA) of three consecutive semester examination results.

\section{Results}

Of the 301 students, only 19 (6.3\%) were male. The percentages of single and multimodal preference learners were almost equal, with $51.50 \%(n=155)$ students having more than one learning style preference. The rest $(48.50 \%, n=146$ students) were single preference learners and included the visual $(4.65 \%)$, auditory $(18.60 \%)$, read \& write $(8.97 \%)$ and kinesthetic (16.28\%) learners.

Of the female students preferring single mode of learning, $4.26 \%$ preferred visual, $19.15 \%$ auditory, $9.57 \%$ read \& write, while $17.02 \%$ preferred kinesthetic mode. Among male students, however, the single mode of preference $\mathrm{V}, \mathrm{A}$, and $\mathrm{K}$ were $(10.53 \%)$, $(10.53 \%), \quad(5.26 \%)$ respectively with none selecting read \& write $(\mathrm{R})$ mode (Table 1$)$. Among the single learning style preference mode female students had a higher percentage than the males in most categories except for visual.

Examinations of semester 2 and 3 were held before the intervention (workshop) and semester 4 after the intervention and the mean GPAs were compared in order to see the impact of intervention on students' academic performance. All the results produced normal distribution and showed some significant difference in means (Figure 1 and Table 2).

Repeated Measure ANOVA test, showed significant $(F(1.69,506.9)=237.2 ; p<.001)$ difference of means in students' academic performance indicated by the GPAs in three consecutive semesters. The mean of GPA2 was 2.45, GPA3 dropped to 2.29 and GPA4 increased to 2.67 .

Table 1: Distribution of students' preferences of learning styles by gender

\begin{tabular}{ccccccc}
\hline CATEGORIES & \multicolumn{2}{c}{ MALE } & \multicolumn{2}{c}{ FEMALE } & \multicolumn{2}{c}{ TOTAL } \\
& Frequency & \% & Frequency & $\%$ & Frequency & $\%$ \\
\hline $\mathbf{V}$ & 2 & 10.53 & 12 & 4.26 & 14 & 4.65 \\
$\mathbf{A}$ & 2 & 10.53 & 54 & 19.15 & 56 & 18.60 \\
$\mathbf{R}$ & 0 & 0.00 & 27 & 9.57 & 27 & 8.97 \\
$\mathbf{K}$ & 1 & 5.26 & 48 & 17.02 & 49 & 16.28 \\
$\mathbf{V + A}$ & 1 & 5.26 & 13 & 4.61 & 14 & 4.65 \\
$\mathbf{V + R}$ & 0 & 0.00 & 8 & 2.84 & 8 & 2.66 \\
$\mathbf{V + K}$ & 0 & 0.00 & 6 & 2.13 & 6 & 1.99 \\
$\mathbf{A + K}$ & 4 & 21.05 & 39 & 13.83 & 43 & 14.29 \\
$\mathbf{R + K}$ & 4 & 21.05 & 20 & 7.09 & 24 & 7.97 \\
$\mathbf{A + R}$ & 2 & 10.53 & 29 & 10.28 & 31 & 10.30 \\
$\mathbf{K + V}$ & 1 & 5.26 & 5 & 1.77 & 6 & 1.99 \\
$\mathbf{V + R + K}$ & 2 & 10.53 & 8 & 2.84 & 10 & 3.32 \\
$\mathbf{A + R + K}$ & 0 & 0.00 & 11 & 3.90 & 11 & 3.65 \\
$\mathbf{V + A + R}$ & 0 & 0.00 & 2 & 0.71 & 2 & 0.66 \\
TOTAL & $\mathbf{1 9}$ & 100.00 & $\mathbf{2 8 2}$ & 100.00 & $\mathbf{3 0 1}$ & 100.00 \\
\hline
\end{tabular}

${ }^{*} V=$ Visual, $A=$ Auditory, $R=$ Read \& Write, $K=$ Kinesthetic 
Figure 1:. Comparison of GPAs of three successive examinations

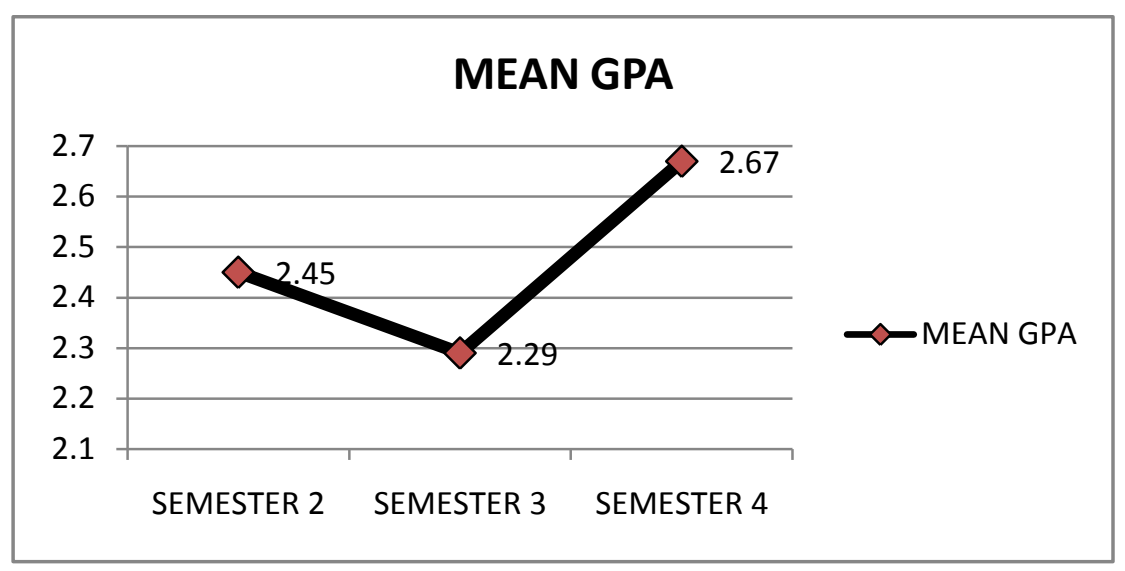

Table 2. Pair wise comparisons GPAs for three successive examinations

\begin{tabular}{ccccccc}
\hline (I)EXAM & (J)EXAM & Mean Difference (I-J) & $\begin{array}{c}\text { Standard } \\
\text { Error }\end{array}$ & Sig. & \multicolumn{2}{c}{$\begin{array}{c}95 \% \text { Confidence Interval } \\
\text { Lower } \\
\text { bound }\end{array}$} \\
$\begin{array}{cccccc}\text { Upper } \\
\text { bound }\end{array}$ \\
\hline 1 & 2 & .155 & .016 & .000 & .117 & .193 \\
& 3 & -.221 & .021 & .000 & -.271 & -.171 \\
2 & 1 & -.155 & .016 & .000 & -.193 & -.117 \\
& 3 & -.376 & .015 & .000 & -.413 & -.340 \\
3 & 1 & .221 & .021 & .000 & .171 & .271 \\
& 2 & .376 & .015 & .000 & .340 & .413 \\
\hline
\end{tabular}

\section{Discussion}

The number of male compared to female nursing students was very small. This is a common scenario in most of nursing colleges in Malaysia where the intake of male students is somewhat restricted. The most probable reason may be the consideration that nursing is more suitable for woman. Both genders received the same exposure and learning experiences and had to finish similar tasks and assignments to fulfil course requirements.

This study found that most male nursing students $(68.4 \%)$ preferred a combination style of learning which was multimodal and female students prefer unimodal learning. Female students who preferred a single mode of information presentation, either visual, auditory, read-write, or kinesthetic and multimodal were (50.17\%) and (49.83\%) respectively. Male students were noted not to prefer "read - write" as a learning style option and this may due to the carefree nature of males compared to females who tend to be more hardworking (conscientious). Wehrwein et al. (2007), reported that although it is known that students have a variety of learning style preferences, it is unknown if gender differences in learning style preferences exists. However Barman et al. (2009) reported significant differences of learning styles preferences by male and female students.

Examinations conducted every semester followed the same procedure recommended by the Malaysia Qualification Agency (MQA) and Nursing Board (NB). All three semesters' results were normally distributed with the average score of GPA varying from 2.29 2.67. The GPA of semester 3 was decreased to 2.29 , either because the syllabus was getting tougher or less preparation by the students as they started the next level of the program. The GPA of semester 4 increased greatly (2.67) after the intervention. The GPA improvement in semester 4 brought out ideas that the workshop may have had some impact on students' academic performance. Students, who had received some information and new ideas on learning styles and study skills during the workshop which had been conducted at early semester, might have applied it and these new knowledge and skills therefore promoted their academic performance in the final examination at the end of the semester. 
Garton et al. (1999) reported that there was a low relationship between the preferred learning style and academic performance. Purdie \& Hattie (1999) reported that the typical study of this genre which specified a variety of study skills and then correlates the scores on tests that measure students' application of these skills with some achievement outcome, typically GPA.

\section{Conclusion and recommendation}

Based on the findings of this study on learning styles conducted for KPTM nursing students, the college may carry out a survey on learning styles to identify students learning preference as they commence their course, tentatively during the orientation week of 1 st semester. Planning learning and counselling interventions compatible with learning style needs of students could promote positive learning outcomes.

\section{Acknowledgement}

This study was conducted under USM short term grant. We like to acknowledge and extend our gratitude to Neil D. Fleming for his permission to use his VARK questionnaire for this study.

\section{References}

Barman, A., Jaafar, R. \& Rahim, A.F.B.A. (2009) Medical Students' Learning Styles in Universiti Sains Malaysia, International Medical Journal, Malaysia, 16, 4, pp. 257-260.

Felder, R.M. \& Brent, R. (2005) Understanding Student Differences, Journal of Engineering Education, 94, 1, pp. 57-72.

Fleming, N.D. (1995) I'm different; not dumb. Modes of presentation (VARK) in the tertiary classroom, In Zelmer, A., (Ed.) Research and Development in Higher Education, Proceedings of the 1995 Annual Conference of the Higher Education and Research Development Society of Australasia (HERDSA), 18, pp. 308-313.

Garton, B.L., Spain, J.N., Lamberson, W.R. \& Spier, D,E. (1999) Learning Styles, Teaching Performance and Student Achievement: A Relational Study, Journal Of Agricultural Education, 40, 3, pp.11-20.

Grasha, A.F. \& Hicks, N.Y. (2000) Integrating Teaching Styles and Learning Styles with Instructional Technology, College Teaching, 48, 1, pp. 2-10.

Griggs, S.A. (1991), Learning Styles Counselling. ERIC Digest. ERIC Identifier: ED341890.
Kinshuk, Liu. T.C. \& Graf, S. (2009) Coping with Mismatched Courses: Students' Behavior and Performance in Courses Mismatched to Their Learning Styles, Education Technology Research and Development, 57, 6, pp. 739-752.

Nursing School and Colleges in Malaysia.(March, 2012)Retrieved from www.etawau.com/edu/ IndexCollegeNursing.htm.

O'Brien, L. (1999) It's Not How Smart You Are....It's How You Are Smart! Retrieved from http://www.newhorizons.org/strategies/styles/obr ien.htm.

Purdie, N. \& Hattie, J. (1999) The Relationship between Study Skills and Learning Outcomes: A Meta-Analysis, Australian Journal of Education, 43, 1, pp. 72-86.

Schroeder, C.C. (1993) New Students - New Learning Styles. Retrieved March 23, 2010 from http://www.virtualschool.edu/mon/Academia/Kier seyLearningStyles.html

Sims, R.R., Sims, S.J. (2006) Maximizing Learning Outcomes in Training and Development: The Critical Role of Learning and Learning Styles, In Sims R.R., Sims S.J. (Eds) Learning Styles and Learning: A Key to Meeting the Accountability Demands in Education, Nova Science Pub Inc.: USA, pp. 259-291.

Sze, S. (2009) Learning Style and the Special Needs Child, Journal of Instructional Psychology, 36, 4, pp. 360-362.

Torres, R.M. (2005) The cognitive ability and learning style of students enrolled in the College of Agriculture at The Ohio State University. In Garton BL, Kitchel T, Ball AL. University Admission Criteria and Learning Style: Predictors of Academic Success? NACTA Journal, Jun 2005. Retrieved from http://findarticles.com/p/articles/mi_qa4062/is_2 00506/ai_n13643624/?tag=content;col1.

Torres, R.M. \& Cano, J. (1994) Learning styles of students in a college of agriculture, Journal Of Agricultural Education, 35, 4, pp. 61-66.

Visser, S., Vreken, N. \& McChlery, S. (2006) Teaching Styles versus Learning Styles in the Accounting Sciences in the United Kingdom and South Africa: A Comparative Analysis, Meditari Accountancy Research,14, 2, pp. 97-112.

Wehrwein, A.E., Lujan, H.L. \& DiCarlo, S,E. (2007)Gender Differences in Learning Style Preferences among Undergraduate Physiology Students, Advances in Physiology Education, 31, pp. 153-157.

Whitney, K. (2005) Understanding Your Learning Style: Study Smart, Pass Quick. Retrieved from http://www.certmag.com/read.php?in=1104. 